\title{
BEHAVIORAL SYNCHRONY IN IBEX GROUPS: EFFECTS OF AGE, SEX AND HABITAT
}

\author{
by
}

\author{
KATHREEN E. RUCKSTUHL ${ }^{1)}$ and PETER NEUHAUS ${ }^{2)}$ \\ (University of Cambridge, Department of Zoology, LARG, Downing Street, \\ Cambridge, CB2 3EJ)
}

(Acc. 27-VII-2001)

\section{Summary}

Synchrony of activities is usually high in foraging groups, possibly to maintain group cohesion. Individuals with different levels of activity budgets, however, may have a hard time synchronizing their behavior to each other without incurring a cost. We predicted that the age and sex structure of a group would affect synchronization levels within a group because of differing individual activity budgets. Individuals in same-sex-age groups were hypothesized to show higher levels of activity synchrony than individuals in mixed sex-age groups. We investigated activity synchrony in adult male, adult female, subadult, and mixed sex-age groups of Alpine ibex - one of the most sexually dimorphic ruminant species. Activity budgets and movement rates were measured to calculate synchrony of activities between group members in June and July 1999. Adult males were more synchronized with group peers than either females or subadults of both sexes. However, while adult males were synchronized in $81 \%$ when in bachelor (adult male) groups, they were only synchronized in $65 \%$ of the time when in mixed sex-age groups. Adult females were synchronized $61 \%$ of their time when in

1) Corresponding author's e-mail address: kruckstuhl@ @otmail.com.

2) We are grateful to the Office Nationale de la Chasse et de la Faune Sauvage and in particular Michel Catusse, Jacques Michallet and Carole Toïgo who permitted this study and provided accommodation and help throughout the study months. The O.N.C. also provided a chalet in the study area and paid for cooking gas. Special thanks go to Carol Toïgo and Manuel Lembke for transportation to and from the study area and for stimulating company. We are grateful for constructive comments on the manuscript made by F. Stephen Dobson, Jan O. Murie, Richard Bon, Jean-François Gérard, Johan G. van Rhijn and an anonymous referee. Thanks again to B.U. Flückiger for the computer program to calculate synchronization indices. This study was financed through a EU Marie Curie fellowship (Improving the Human Research Potential and the Socio-Economic Knowledge Base) granted through the Swiss National Science Foundation to K.E. Ruckstuhl. 
mixed sex-age groups and 69\% when in female groups. Individual subadult males displayed higher synchrony when in bachelor or female groups than when in mixed sex-age or subadult mixed-sex groups. Subadult groups and mixed sex-age groups showed the lowest degree of synchrony of all group types. In general, animals in groups of same body-sized individuals were more synchronized with their group members than animals in mixed body-size groups. Two and three year-old males did not adjust their time spent lying to the group but their time spent walking. They also tended to change their time spent grazing and standing according to group type. Among subadults, females spent more time foraging than males but less time lying and standing. There was no difference in time spent walking. Bachelor and subadult groups had the greatest movement rates while female groups were relatively sedentary within escape terrain. Individuals in escape terrain did only marginally synchronize their behavior to each other likely because groups did not move much and synchrony was presumably less important. We conclude that habitat type, group movement rates, and a group's sex-age composition may affect the extent to which an individual will synchronize its activities to the other group members.

Keywords: synchrony, sexual segregation, group living, habitat selection.

\section{Introduction}

In sexually size-dimorphic social ungulates, adult males and females segregate into single sex groups outside the breeding season (Main et al., 1996). Within these groups, individual activity budgets are similar and synchrony of activities generally high (Conradt, 1998; Ruckstuhl, 1998, 1999; Conradt \& Roper, 2000). Synchronizing activities with other group members could be viewed as an adaptation to maintain contact with the group (Jarman, 1974), to gain benefits of decreased predator pressure by dilution and predator detection effects (Hamilton, 1971; Dehn, 1990). Further, Ruckstuhl (1998, 1999) proposed that individuals of dissimilar body size to the other group members might pay a cost when having to synchronize their behavior to other group members, because they may not be able to follow their optimal activity budget.

The Alpine ibex (Capra ibex ibex) is one of the most dimorphic ruminant species (Nowak, 1991), and as such ideal to study the consequences of body size dimorphism on synchrony in different types of group. Male ibex have much larger and heavier horns than females, and are about double the weight of adult females (Weckerly, 1998). Young subadult male ibex of intermediate body size between adult males and females sometimes form groups of their own, but can also be found in either adult male or female (nursery) groups 
(Villaret \& Bon, 1995, 1998). We collected data on activity budgets of ibex to analyze synchrony of activities in different kinds of groups. Groups were composed either of adult males, adult females, subadults or mixed sex-age groups.

Adult males and females were expected to greatly differ in their time spent in different activities. These differences in activity budgets would result in relatively low degrees of activity synchronization in mixed-sex groups whereas we expected higher degrees of synchrony in same sex-age groups.

Ruckstuhl (1998) proposed, that while differences in activity patterns may lead to sexual segregation, differences in movement rates due to predator avoidance may further increase the degree of spatial segregation between the sexes. Higher movement rates of females to avoid predation have been reported for example for caribou females (Rangifer tarandus) (Bergerud et al., 1984; Bergerud \& Page, 1987), while the use of escape terrain to evade predation has been reported for various mountain ungulates such as for example Nubian ibex (Capra ibex nubiana) (Kohlmann et al., 1996) or Alpine ibex (Couturier, 1962; Toïgo, 1999). Ibex have co-evolved with their natural predators the wolf (Canis lupus), European lynx (Felis lynx) and golden eagle (Aquila chrysaëtos) (Couturier, 1962). Although wolves have been absent from most of the French Alps for more than a century, ibex still show predator avoidance behavior, such as group formation, vigilance for predators, and the use of escape terrain, especially by females close to or after parturition (Toïgo, 1999).

If ibex kids were more vulnerable to predation than adults, we expected reproducing females either to increase their use of escape terrain or to show higher movement rates when with kids. Adult males, which are less vulnerable, would be expected to make less use of escape terrain during that period or to have lower movement rates. We therefore documented movement rates activity budgets and synchrony of activities in different group types according to age, sex and habitat in the first two months after the kids were born.

\section{Study area, animals and methods}

The Belledonne-Sept-Laux Reserve is located in the Pre-Alps of Isère, France (Toïgo, 1998). The reserve is managed by the Office National de la Chasse et de la Faune Sauvage (O.N.C.). Most areas used by ibex were south or east facing slopes. Observations were done in the 
subalpine and alpine zones between 2,000 and 2,500 m above sea level. Data were collected in June and July 1999, when most kids were born in the study population. All focal ibex were individually marked with plastic ear tags and their exact age was known. Observations were made on 48 adult females ( 7 non- and 41 lactating females of age $3+$ ), 9 yearling females, 2 two-year-old non-lactating females, 44 adult males (age $4+$ years), 8 yearling males, 12 two-year-old males, and 5 three-year-old males. We used binoculars $(10 \times 42)$ and spotting scopes $(25-40 \times 60$ zoom) for all observations.

The ibex of this study population typically formed four group types: female groups (including adult females, kids and subadults of both sexes), bachelor groups, mixed sex-age groups (adults of both sexes and subadults) and subadult groups (males $<4$ years of age and females $<3$ years of age). Females were considered adults at 3 years of age or older, males from the age of 4 . We do not have measurements of body mass for the different ages and sexes in ibex but measurements of heart girth (circumference of the breast), which is an excellent indicator of actual body mass in ibex (Toïgo, 1998). Although females only attain maximum body mass and heart girth between the age of 4 and 6, they usually have their first or second kid by the age of 3. At age 3 or 4 males attain adult female heart girth. After the age of 4 , a male's heart girth steadily increases up to the age of 10 to 12 (Toïgo, 1998), during that time their body mass may increase from 60 to $100 \mathrm{~kg}$ (Toïgo, 1998). The ibex were habituated to people and easy to observe. However, all observations were made from a distance of 200-400 meters to minimize disturbance.

To construct individual time budgets (time spent grazing, lying, standing or walking) and to evaluate synchrony, we selected a group and observed them for 8-12 h/day. We defined walking as a forward movement with the head held above shoulder height. Time spent with the head close to vegetation was counted as time spent grazing. If an individual ibex changed its behaviour for $1 \mathrm{~min}$ or more we considered that it had started a new activity bout. Behaviour that lasted less than a minute was not recorded. This approach was used because it would have been impossible for the observer to register all short shifts in behavior (less than a minute) of each focal animal simultaneously. Ibex sometimes lifted their head when grazing to scan the environment for up to 5 seconds (alert posture). This sporadic behavior, for example, was not noted as a shift in behavior because it lasted less than a minute.

The date, time, location, identity number (from ear tags), age and sex of all focal ibex, and the number of animals in the group were noted. A group of ibex in our study area usually ranged between 5 and 25 individuals in June and July with an average of around 12. Groups had to be at least 100 meters apart to be considered two separate groups. All members of a group were monitored at the same time.

For each focal animal in the group, the transition time from one behavior to another was recorded over the entire observation period (see also Ruckstuhl, 1998, for methods). All observations that lasted less than 6 hours were excluded from analyses. The sexes were sampled equally across the two months and observed over all daylight hours. A total of 1148 ibex-hours of observation were collected. We observed 10 different female groups, 8 different bachelor groups, 3 different mixed sex-age groups and 3 subadult groups.

Some ibex were sampled in different groups and the possibility of pseudo-replication exists (Machlis et al., 1985; Martin \& Kraemer, 1987; Leger \& Didrichsons, 1994). The maximum of repeated measures for the same individual was 4 with an average of 2 for all individuals over the two months of the study. However, we avoided resampling the same individuals, or waited at least one week between repeated observations of the same animal. Individuals within a group were affected in their behavior by other group members and by 
what they had done previously. We cannot exclude influences through other group members, but believe, given the long-time observation of the same individuals during a day within a group, that all individuals have been treated equally and that the data accurately represent daily activity rhythms. If problems of pseudo-replication or dependence of data exist, they are similar for all individuals.

To assess the distance traveled by a group during time budgets, we noted its exact travel route on a map (1:15000) and calculated total distance traveled over the observation period. To get a measure of movement rate for the different group types, we divided the total distance traveled by the number of hours the group was observed. Habitat types were either classified as escape terrain, with rocky outcrops and steep cliffs or as open, grassy, less steep meadows without cliffs. From direct observations, we could then calculate the percentage of time each group was using the two different habitat types.

\section{Data analysis}

An index for synchrony of behavior was calculated using the following method described by Ruckstuhl (1999): based upon time budget data, we assigned a value, either inactive $=1$ or active $=2$, to all focal animals each minute they had been observed, using a program in Borland Pascal V 7.01. Grazing, walking and standing were considered active behaviours, and lying was considered inactive behaviour.

A synchronization factor $\left(S_{f}\right)$ was then calculated for each minute. The first individual (randomly taken from the list) was regarded as reference-individual and its behavior was assigned a value based on its degree of synchrony with other group members as follows: if the reference-individual was inactive, but more than half of the group members were active, the synchronization factor for that individual in that minute was zero. If it had the same activity as most of the other group members, then its synchronization factor for that minute was one. If half of the animal's group mates were active whilst the other half were inactive all the group mates' behavior was assigned to be either active or inactive, through tossing of a coin. After this procedure, the synchrony of the focal individual $\left(\mathrm{S}_{\mathrm{f}}\right)$ with his group mates could be assessed as either zero or one for that particular minute.

After the synchronization factors for each minute were calculated for the whole activity budget (360-720 minutes) of the reference-individual, a mean synchronization index ( $S_{\text {index }}$ ) was calculated for that individual:

$$
\mathrm{S}_{\text {index }}=\Sigma\left(\mathrm{S}_{\mathrm{f}}\right) / \mathrm{n}, \quad \mathrm{n}=\text { number of minutes observed }
$$

This procedure was repeated for each group member, and multiplied by 100 the synchronization indices basically represent the percentage of time each individual was in synchrony with most of the other group members.

Prior to statistical analyses all data were tested for normality (normal probability plots, Lilliefors test) and homoscedasticity (Bartlett-Box F) using the SPSS statistics package (Norusis, 1993). All percentages (e.g. synchronization indexes) were arcsine square-root transformed to meet the assumptions of normal distribution for parametric tests (Siegel \& Castellan, 1988). If transformation did not result in normality or sample sizes were too small, we applied non-parametric tests. Means are reported \pm standard error (SE). Where non-parametric statistics were applied, the median is given with the minimum and maximum values and the interquartile range (IQR). Non-significant p-values are followed by $95 \%$ confidence intervals (CI), as recommended by Johnson (1999) and Steidl et al. (1997). 
Differences in activity budgets and differences in synchrony were analyzed according to group type and an individual's sex and age-class (yearling, subadult or adult) using either ANOVA, or Kruskal-Wallis and Mann-Whitney $U$-tests (for non-normal data). For multiple comparisons we used Bonferroni adjusted $p$-values.

Correlation between group size or an individual's age and synchronization index were calculated with Spearman rank order correlation (Siegel \& Castellan, 1988). Group size and individual synchrony were significantly correlated in females $\left(r_{\mathrm{s}}=0.67, p<0.001\right)$ but not in males $\left(r_{\mathrm{s}}=-0.19, p=0.86\right)$. We therefore corrected the synchronization indices for females by dividing them by group size, as recommended by (Engel \& Lamprecht, 1997), and used the adjusted synchronization values for all comparisons.

Differences in movement rates according to group type were tested using Mann-Whitney $U$-tests, again with Bonferroni adjusted $p$-values.

\section{Results}

Of 30 observation days (about 100 groups sampled) on activity budgets in June and July, adult females and males were only seen in mixed-sex-age groups on three occasions: once a non-lactating female joined a bachelor group, and the two other times a 6-year-old male joined a female group. On all other occasions adult males and females were strictly segregated. Among adult males or females, there was no correlation between an individual's age and the percentage of time it was synchronized in its activity with other individuals in the group $\left(r_{\mathrm{s} \text { females }}=-0.15, p=0.31, N=59\right.$ females; $r_{\text {s males }}=-0.08, p=0.57, N=69$ males $)$.

When in a group, adult male ibex were the most synchronized sex-age class. Adult males were significantly more synchronized with group peers than either females or subadults of both sexes (Fig. $1 ; F_{\text {overall }}=10.68$, $\mathrm{df}=2, p<0.0001$, significant differences in synchrony were found between adult males and females and adult males and subadults; post-hoc Scheffé tests $p<0.05)$. However, the degree of synchrony found in adult males depended on the type of group that they were in. In bachelor groups, males were synchronized with other group members during $81 \pm 0.2 \%(N=50$ individuals ) of their time while they only synchronized in $65 \pm 0.1 \%(N=2$ individuals ) of their time when in mixed sex-age groups $(U=9.5, p<$ 0.05). Females were only synchronized during $61 \pm 1 \%(N=4$ individuals; $\min =55 \%, \max =69 \%, \mathrm{IQR}=12 \%)$ with other members of the group when in mixed sex-age groups and $69 \pm 1 \%(N=41$ individuals; min = $43 \%, \max =95 \%, \mathrm{IQR}=27 \%)$ when in female groups $(U=60, p=0.41)$. 


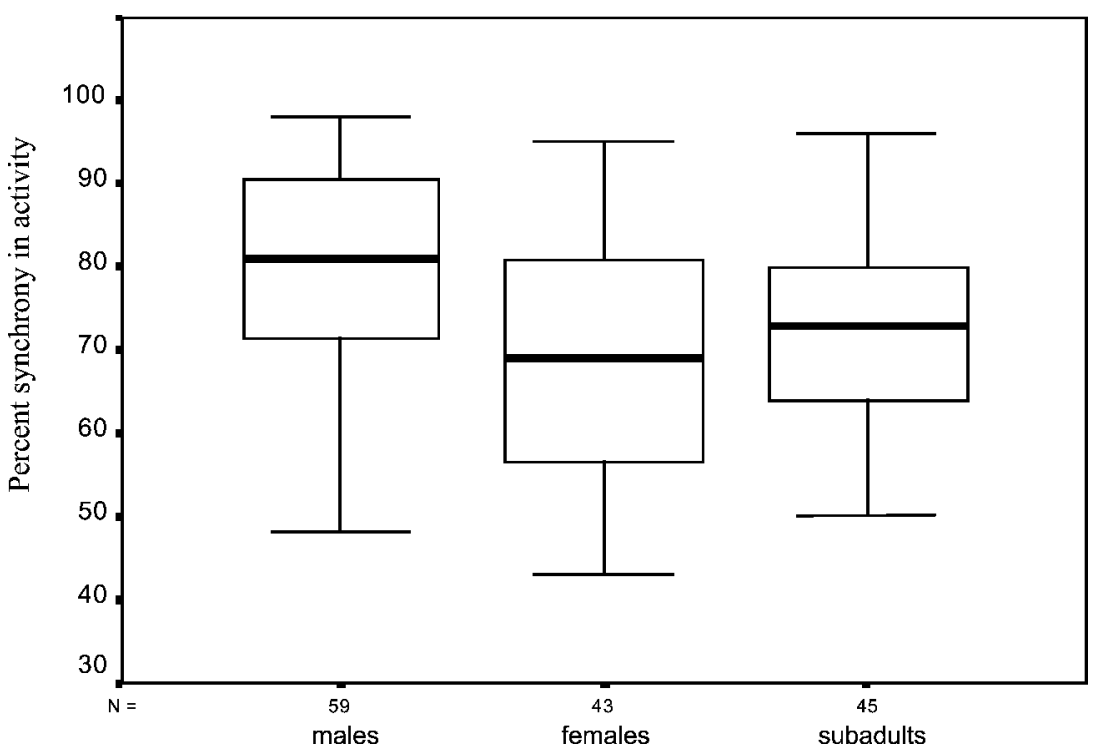

Fig. 1. Percentage of time an individual of a certain sex-age class was synchronised in its behaviour to its group mates (all group types pooled). $N=$ number of individuals used. Males, females and subadults are different sex-age classes. The mean with interquartile range, minima and maxima are shown (even though the data are normally distributed).

Subadult males $(<4$ years old $)$ displayed the highest degree of synchrony when in female or bachelor groups, but much less synchrony when in mixed sex-age or subadult male-female groups (Fig. $2 ; F=4.29$, df $=3$, $p<0.05)$. Significant differences were found between female and mixed sex-age groups, bachelor and mixed sex-age groups, and bachelor and subadult mixed groups (post-hoc Scheffé tests $p<0.05$ ). Among subadult males, yearlings were synchronizing their behavior more often to other group members $(76 \pm 1 \%, N=4$ individuals ) than $2-3$ year olds $(64 \pm 1 \%$, $N=6$ individuals $)(U=200, p<0.005)$. In contrast to subadult males, subadult females did not significantly differ in their synchrony with other group members in either female or subadult groups $(U=7.50, \mathrm{df}=1)$. Subadult females were synchronized in $81 \pm 1 \%(\mathrm{CI}=67-91 \% ; N=6$ groups) of the time when in adult female groups and $70 \pm 1 \%(\mathrm{CI}=44$ 93\%; $N=4$ groups), when in subadult groups.

Adult females spent much more time grazing $(z=-7.68, p<0.0001$, $N=45$ females and 56 males $)$ and less time lying $(z=-4.11, p<0.001)$ and walking $(z=-3.62, p<0.0001)$ than adult males (Table 1). Females 


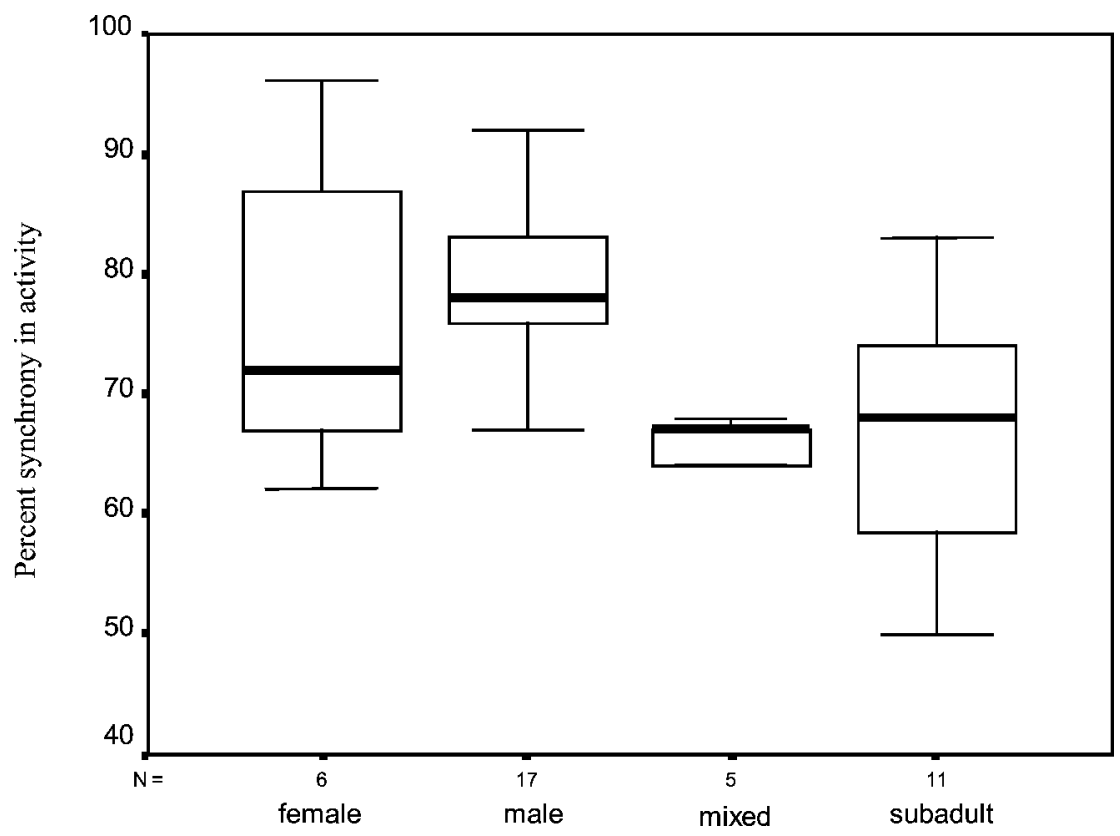

Fig. 2. Percentage of time subadult males were synchronised in their behaviour with their group mates. Each box plots represent the degree of synchrony of subadult males when in a specific group type (female, male, mixed, and subadult). $N=$ number of subadult males observed. The mean with interquartile range, minima and maxima are shown (even though the data are normally distributed).

and males spent a similar time standing (Table $1 ; z=-1.19, p=0.23$ ). Two and 3-year old males did not adjust their time spent lying according to the group type they were in (Kruskal-Wallis $\chi^{2}=0.14, p=0.99$, $\mathrm{df}=3$, Table 1$)$, but they adjusted their time spent walking $\left(\chi^{2}=16.25\right.$, $p<0.01$ ) (Table 1). Subadult males also tended to change the percentage of time they spent grazing $\left(\chi^{2}=7.12, p=0.07\right)$ and standing $\left(\chi^{2}=6.91\right.$, $p=0.07$ ) depending on group type (Table 1). Among subadults, females spent more time foraging than males $(U=24, p<0.0001)$, but less time lying $(U=66, p<0.01)$ or standing $(U=68, p<0.01)$ (Table 1$)$. There was no difference in the time spent walking $(U=131, p=0.39$, Table 1$)$.

Bachelor (59 \pm 2 meters/hour, 10 groups) and subadult groups $(61 \pm 2 \mathrm{~m} / \mathrm{h}$, 3 groups) traveled the most during observation hours, while female (34 \pm $2 \mathrm{~m} / \mathrm{h}, 10$ groups) and mixed age-sex groups ( $24 \pm 1 \mathrm{~m} / \mathrm{h}, 3$ groups ) moved around much less and stayed in restricted areas of escape terrain (KruskalWallis $=66.50, p<0.0001)$. Females with young were in escape terrain 


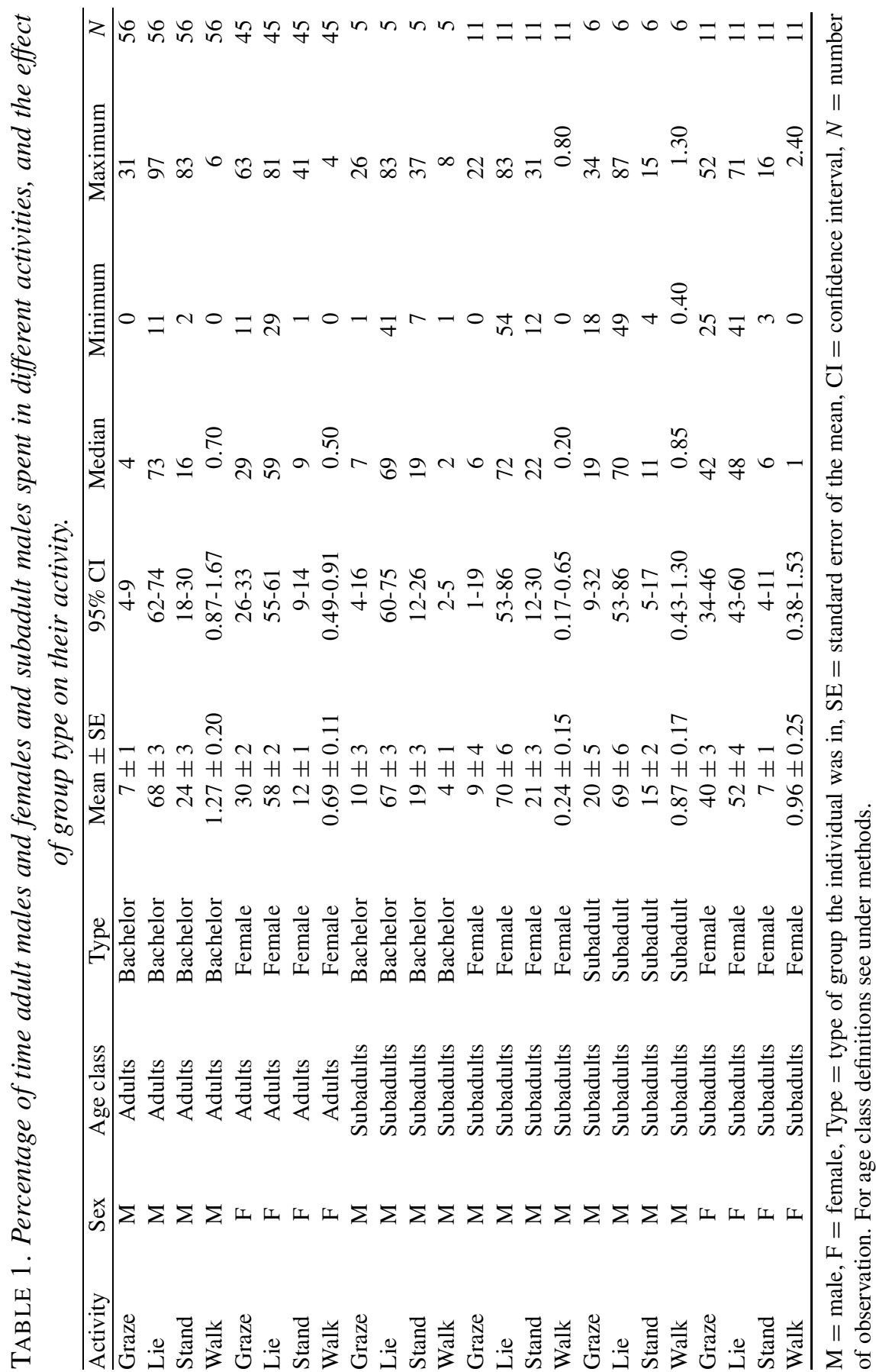


in $100 \%$ of all observations (8 observation days on female groups), while bachelor groups mainly used grassy slopes (75\% of observations, 6 days) and less escape terrain (25\%, 2 days). Females without young and subadults used both escape terrain and grassy slopes, depending on the type of group they were in. Before parturition in mid June, non-reproductive females used grassy slopes (22\% of observations, 2 days) when in a group of nonreproductive females but joined females with young after the first kids were born (78\% of observations, 7 days). Subadult groups used grassy slopes and escape terrain equally (50\% each, 4 days).

\section{Discussion}

Synchrony in ibex groups changed with group type and possibly also with habitat type (grassy slopes versus escape terrain) and the extent to which individuals synchronized their behavior to other group members was very variable. Conradt (1998) and Ruckstuhl (1998, 1999) argued that males and females of sexually dimorphic ungulate species segregate into different groups because of incompatibilitie s of activity budgets, and potential costs of synchrony. Our results suggest that animals in groups composed of same body-size individuals were indeed more synchronized in their activities, than individuals in mixed body-size groups. In agreement with this, adult male ibex showed the highest synchrony of activities when in bachelor groups and considerably less synchrony when in mixed sex-age groups. Although we only observed ibex in June and July, when behavioral differences between the sexes are likely biggest, female ibex of our study population consistently spent more time grazing than adult males in all other months of the year and were segregated outside the breeding season (Toïgo, 1998).

Ruckstuhl (1999) and Ruckstuhl \& Festa-Bianchet (2001) argued that segregation should not only happen by sex but also by age because subadult males in subadult groups could facilitate synchrony and optimize activity budgets. Segregation by age has been observed in Nubian ibex (Gross et al., 1995), mouflon (Ovis gmelini) (Cransac et al., 1998) and some other social ungulates (Estes, 1991). Accordingly, Villaret \& Bon (1995) and later Villaret et al. (1997) found that male ibex were often in the company of similar-aged peers, while yearling males were primarily found in female groups. Subadult males of our study population, however, did not form 
groups of their own but either joined bachelor groups, female groups or mixed with subadult females. Subadult males varied the degree of synchrony of their activities according to the group type they were in. That is for example reflected in the amount of time they spent foraging in different groups: while they spent $20 \%$ of their time foraging when in subadult mixedsex groups, they only spent $10 \%$ of their time foraging when in either bachelor or female groups. In mixed subadult groups, the subadult males in particular exhibited less synchronized behavior, while subadult females kept the same level of synchrony independent of group type.

As Ruckstuhl (1998) suggested, compatibility of activity budgets and synchrony may be key factors affecting sexual and age segregation, but big differences in movement rates between the sexes could further increase spatial and social segregation. Adult female bighorn sheep for example spent much more time grazing than adult males and females moved 4 times further during a day than males (Ruckstuhl, 1998). Male and female ibex differed greatly in their activity budget, but contrary to bighorn sheep, female ibex with young spent most of their time in very steep escape terrain. Before parturition, female ibex without young roamed freely within the study area using grassy meadows but tended to associate with females and their young in escape terrain after the young were born.

Females with young stayed in escape terrain in June and July and therefore favored habitat that was presumably safe in terms of predation to their young. Despite the fact that predators have been absent from our study area for a long time, the ibex's behavior likely was influenced over evolutionary time by former avoidance of their terrestrial predators, such as the wolf, lynx and human hunters (Couturier, 1962). The wolf is starting to re-colonize some of its former ranges in the French Alps (Toïgo, 1999). That female ibex with young do select escape terrain to avoid predation was clearly demonstrated in a study done on Nubian ibex: when young Nubian ibexes were accidentally confined in a protected area, females selected richer feeding grounds, foraged further away from escape terrain and spent more time foraging than mothers with young at heel (Kohlmann et al., 1996).

Adult males in our study area did not often stay in escape terrain. Bachelor groups frequently traveled from one valley to the next and had a much higher average movement rate than females. Forage seemed to be more abundant at lower altitudes, and by traveling around males could have selected better forage than females. We did not evaluate quality or quantity of forage 
available in the different areas, but we noted that females left escape terrain more often towards the end of July, feeding in the same areas as adult males, although not in the same groups.

The question then arises why adult male ibex did not join female groups in escape terrain when no synchrony is required. One possible explanation may be that food is usually scattered in escape terrain and large aggregation s of animals would be impossible (Francisci et al., 1985). As big males do not need as much predator protection they could afford to forage along the valleys and grassy slopes where forage was more abundant. Villaret et al. (1997), who studied ibex in the French Alps (Bargy massif), found sexual segregation by habitat during and shortly after parturition (June-July) but less habitat segregation in summer when males and females used similar habitat. In August females of their study population moved into grassland areas and spent less time in cliffs than shortly after parturition in June and July. However, despite males and females using the same habitat they were still segregated into different sex groups (Villaret et al., 1997).

If we compare synchronization indices of ibex with those for bighorn sheep (Ruckstuhl, 1999), bighorn sheep were about 10\% more synchronized with their group's behavior than ibex. Adult male ibex had about the same level of synchrony as bighorn mixed-sex-age groups (Ruckstuhl, 1999), and the synchronization index was even lower for female, subadult or mixed-sex ibex groups. One explanation why ibex groups were less synchronized than bighorn sheep groups could be that especially female, subadult, and mixed sex-age groups spent their time almost exclusively in steep escape terrain, where they did not necessarily need to synchronize their behavior to maintain group cohesion. The fact that they all choose the same type of habitat and did not move around much made them aggregate even if they may not have been actively seeking to form a group. Although these animals were within a defined group of loosely associated animals, they likely followed their own optimal activity budgets and hence were much less synchronized with their group mates than, for example, members of bachelor groups with their high movement rates.

We conclude that a number of factors drive an individual's group choice and its degree of synchrony with other group members, such as an animal's age, sex and body-size, but also external factors such as habitat type, predation risk or group compositions. We have shown that the potential importance of synchrony for group cohesion and its associated costs can 
be lessened if groups exist owing to habitat selection. Costs for synchrony could, for example, be measured as energy expenditure or energy assimilation depending on an individual's choice of groups and or habitat. Studies on synchrony of activities are lacking for most ungulate species and other mammals. Further research is needed on the factors affecting an individual's group choice and its synchrony of activities with its group mates to understand the potential implications for sexual and age segregation - a phenomenon that is wide spread among many ungulate species and other mammals.

\section{References}

Bergerud, A.T., Butler, H.E. \& Miller, D.R. (1984). Antipredator tactics of calving caribou: dispersion in mountains. - Can. J. Zool. 62, p. 1566-1575.

— — \& Page, R.E. (1987). Displacement and dispersion of parturient caribou at calving as antipredator tactics. — Can. J. Zool. 65, p. 1597-1606.

Conradt, L. (1998). Could asynchrony in activity between the sexes cause intersexual social segregation in ruminant. - Proc. Roy. Soc. Lond. 265, p. 1359-1363.

- — \& Roper, T.J. (2000). Activity synchrony and social cohesion: a fisson-fusion model. — Proc. Roy. Soc. Lond. 267, p. 2213-2218.

Couturier, M.A.J. (1962). Le bouquetin des Alpes. - Arthaud, Grenoble, France.

Cransac, N., Gerard, J.-F., Maublanc, M.-L. \& Pépin, D. (1998). An example of segregation between age and sex classes only weakly related to habitat use in mouflon sheep (Ovis gmelini). — J. Zool. Lond. p. 244, 371-378.

Dehn, M.M. (1990). Vigilance for predators: detection and dilution effects. - Behav. Ecol. Sociobiol. 26, p. 337-342.

Engel, J. \& Lamprecht, J. (1997). Doing what everybody else does? A procedure for investigating behavioural synchronization. - J. theor. Biol. 185, p. 255-262.

Estes, R.D. (1991). The behavior guide to African mammals. Including hoofed mammals, carnivores, primates. - University of California Press, Berkley.

Francisci, F., Focardi, S. \& Boitani, L. (1985). Male and female alpine ibex: phenology of space use and herd size. - In: The biology and management of mountain ungulates (S. Lovari, ed.) Croom Helm, London, p. 124-133.

Gross, J.E., Alkon, P.U. \& Demment, M.W. (1995). Grouping patterns and spatial segregation by Nubian ibex. - J. Arid Envir. 30, p. 423-439.

Hamilton, W.D. (1971). Geometry for the selfish herd. - J. Theor. Biol. 31, p. 295-311.

Jarman, P.J. (1974). The social organisation of antelope in relation to their ecology. Behaviour 48, p. 215-267.

Johnson, D.H. (1999). The insignificance of statistical significance testing. - J. Wildl. Manage. 63, p. 763-772.

Kohlmann, S.G., Müller, D.M. \& Alkon, P.U. (1996). Antipredator constraints on lactating Nubian ibexes. - J. Mammal. 77, p. 1122-1131.

Leger, D.W. \& Didrichsons, I.A. (1994). An assessment of data pooling and some alternatives. - Anim. Behav. 48, p. 823-832. 
Machlis, L., Dodd, P.W.D., Fentress, R. \& Fentress, J.C. (1985). The pooling fallacy: problems arising when individuals contribute more than one observation to the data set. - Z. Tierpsychol. 68, p. 201-214.

Main, M.B., Weckerly, F.W. \& Bleich, V.C. (1996). Sexual segregation in ungulates: new directions for research. - J. Mammal. 77, p. 449-461.

Martin, P. \& Kraemer, H.C. (1987). Individual differences in behaviour and their statistical consequences. - Anim. Behav. 35, p. 1366-1375.

Norusis, M.J. (1993). SPSS for Windows. — SPSS Inc., Chicago.

Nowak, R.M. (1991). Walker's mammals of the world. - John Hopkins University Press, Baltimore.

Ruckstuhl, K.E. (1998). Foraging behaviour and sexual segregation in bighorn sheep. Anim. Behav. 56, p. 99-106.

- - (1999). To synchronise or not to synchronise: a dilemma in young bighorn males? Behaviour 136, p. 805-818.

— — \& Festa-Bianchet, M. (2001). Group choice by subadult male bighorn sheep: trade-offs between foraging and predator avoidance. - Ethology 107, p. 161-172.

Siegel, S. \& Castellan, N.J. (1988). Nonparametric statistics for the behavioral sciences. McGraw-Hill, Inc., New York.

Steidl, R.J., Hayes, J.P. \& Schauber, E. (1997). Statistical power analysis in wildlife research. - J. Wildl. Manage. 61, p. 270-279.

Toïgo, C. (1998). Stratégies biodémographiques et sélection sexuelle chez le bouquetin des alpes (Capra ibex ibex). - PhD thesis, Claude Bernard, Lyon 1, Lyon.

— - (1999). Vigilance in lactating female Alpine ibex. — Can. J. Zool. 77, p. 1060-1063.

Villaret, J.C. \& Bon, R. (1995). Social and spatial segregation in Alpine Ibex (Capra ibex) in Bargy, French Alps. — Ethology 101, p. 291-300.

- — \& - - (1998). Sociality and relationships in Alpine ibex (Capra ibex). — Rev. Ecol. (Terre Vie) 53, p. 153-170.

- — - — — \& Rivet, A. (1997). Sexual segregation of habitat by the alpine ibex in the French Alps. — J. Mammal. 78, p. 1273-1281.

Weckerly, F.W. (1998). Sexual-size dimorphism: influence of mass and mating systems in the most dimorphic mammals. - J. Mammal. 79, p. 33-52. 